\title{
ARROGANCE AND DEEP DISAGREEMENT
}

\author{
ANDREW ABERDEIN*
}

I intend to bring recent work applying virtue theory to the study of argument to bear on a much older problem, that of disagreements that resist rational resolution, sometimes termed "deep disagreements". Just as some virtue epistemologists have lately shifted focus onto epistemic vices, I shall argue that a renewed focus on the vices of argument can help to illuminate deep disagreements. In particular, I address the role of arrogance, both as a factor in the diagnosis of deep disagreements and as an obstacle to their mutually acceptable resolution. Arrogant arguers are likely to make any disagreements to which they are party seem deeper than they really are and arrogance impedes the strategies that we might adopt to resolve deep disagreements. As a case in point, since arrogant or otherwise vicious arguers cannot be trusted not to exploit such strategies for untoward ends, any policy for deep disagreement amelioration must require particularly close attention to the vices of argument, lest they be exploited by the unscrupulous.

\section{The Second Highest Mountain}

Alice: Everyone knows Mount Everest is the world's highest mountain, but what's the second highest?

Bob: Isn't it Kanchenjunga? That rings a bell.

Alice: I'm not sure-that doesn't sound right.

Alice and Bob are in disagreement. Bob thinks Kanchenjunga is the world's second highest mountain; Alice is not sure. Of course, there are easy remedies for disagreements of that sort:

Bob: O.K., let's look it up. World's highest mountains... here we go, "Everest 29,029 ft, 8,848 m; K2 28,251 ft, 8,611 m; Kanchenjunga 28,169ft, 8,586 m". So I was wrong-it's not Kanchenjunga, it's K2. Funny name.

Disagreement solved! Thank you Google and Wikipedia. But wait...

Alice: Hang on, doesn't Everest have two peaks? I'm sure I read that somewhere. Where's the other peak on the list?

Bob: I don't see it. Maybe it's much shorter than the main peak?

Alice: Let's check. South Summit of Everest... "28,704 ft, 8,749 m". That's weird-it's higher than Kanchenjunga or K2! Why's it not on the list?

Bob: One peak per mountain maybe?

Alice: No, that can't be right! Look at Gasherbrum! It's got four summits in the top twenty. It must be a mistake. More fool me to trust Wikipedia.

Bob: No, Wikipedia isn't perfect, but this is the sort of stuff it gets right. We must be overlooking something.

Now we have a disagreement that is not so easily remedied, at least with the resources available to Alice and Bob. Perhaps they consult Charley, a mountaineer:

Charley: I see the confusion. Everest does have two peaks and they're both higher than K2. But the South Peak doesn't count in lists of highest peaks because

*School of Arts \& Communication, Florida Institute of Technology, Melbourne FL.

Date: January 29, 2020. 
it's not prominent enough. Prominence measures how much a mountain sticks up-how far down you would have to climb before you could start climbing anything taller. For K 2 that's thousands of feet; but for the South Peak it's only thirty feet or so. It's little more than a pimple off the side of Everest. Indeed the standard route up Everest runs over the top of the South Peak. Lists of highest peaks have prominence thresholds. Even the most inclusive, with millions of included peaks, require a hundred feet or so of prominence, more than three times the prominence of the South Peak.

Bob: I get it. The Wikipedia list is right after all!

Alice: Not so fast! The South Peak is a peak, however small, and it's higher than everything on Earth except the main peak. It should be in second place, whatever the geographers say!

Alice and Bob are now disagreeing more profoundly. They are not just disagreeing over their different beliefs or the sources of those beliefs, they are disagreeing over the process by which those beliefs can be confirmed or falsified. It's not clear what the best way forward at this point may be. This could be an example of what has come to be known as a deep disagreement.

\section{Deep Disagreement}

Deep disagreements have attracted substantial attention recently within both epistemology and informal logic. Michael Lynch proposes the following helpful definition of a deep disagreement, as requiring four conditions:

(1) Commonality: The parties to the disagreement share common epistemic goal(s).

(2) Competition: If the parties affirm distinct principles with regard to a given domain, those principles

(a) pronounce different methods to be the most reliable in a given domain; and

(b) these methods are capable of producing incompatible beliefs about that domain.

(3) Non-arbitration: There is no further epistemic principle, accepted by both parties, which would settle the disagreement.

(4) Mutual Circularity: The epistemic principle(s) in question can be justified only by means of an epistemically circular argument (Lynch, 2010, 265).

Returning to Alice and Bob's disagreement, we may see that they satisfy Commonality, at least assuming they are both sincere in their desire to identify the world's second highest mountain. Alice's insistence on absolute height in contrast with Bob's deference to the geographers' prominence threshold criterion may be seen as a difference of principle consistent with Competition. If Alice is not prepared to accept Charley's account (or that of any other such expert), the disagreement would also meet the Non-arbitration criterion. We have not yet seen enough of Alice and Bob's epistemic principles to determine whether they exhibit Mutual Circularity, but things do seem to be headed that way.

The literature on deep disagreement begins with Robert Fogelin. Fogelin does not maintain that deep disagreements are common, nor that all tough disagreements must be deep. For Fogelin, a deep disagreement necessarily involves "a clash in underlying principles", "framework propositions", or worldviews (Fogelin, 1985, 5). So epistemic principles satisfying Lynch's Non-arbitration and Mutual Circularity criteria would be grounded in rival worldviews. Fogelin does explicitly invoke what we may identify as argumentational virtues-being "unbiased, free of prejudice, consistent, coherent, precise and rigorous" (Fogelin, 1985, 
5). However, he does so to reject the prospect that they may prevent deep disagreements: parties exhibiting such qualities may "still disagree ... profoundly, not just marginally" (ibid.). Strictly speaking, Fogelin is not committed to there being no relationship between the disputants' characters and deep disagreement, since he leaves open the possibility that argumentational vice could still make deep disagreements worse, even if argumentational virtue would not make them better. But Fogelin is careful to distinguish the depth of a disagreement from its emotional intensity, the strength of feeling with which the disputants maintain their positions. Indeed, deep disagreements can be debated dispassionately, even if they are more often rancourous. John Stuart Mill helps to explain why some such disagreements, at least, are so often linked to strong feelings:

So long as an opinion is strongly rooted in the feelings, it gains rather than loses in stability by having a preponderating weight of argument against it. For if it were accepted as a result of argument, the refutation of the argument might shake the solidity of the conviction; but when it rests solely on feeling, the worse it fares in argumentative contest, the more persuaded its adherents are that their feeling must have some deeper ground, which the arguments do not reach: and while the feeling remains, it is always throwing up fresh intrenchments of argument to repair any breach made in the old (Mill, 1977 [1869], 261).

Although Fogelin is concerned with cases where disagreement really does proceed from "deeper ground", for Mill the appeal to conflicting worldviews may be illusory or insincere. Nonetheless, intensity of emotion is to be expected in either case. Much more recently, Michael Hannon has argued that many apparent disagreements are illusory, perhaps especially those disagreements most associated with political polarization (Hannon, 2019, 2020). Hannon draws on empirical studies which suggest that polling data usually taken to indicate sharp disagreement may be better understood as "expressive responding", intended primarily to signal the respondents' allegiance (Schaffner and Luks, 2018). As Hannon notes, not only does this suggest that there are fewer disagreements than meet the eye, deep or otherwise, but also that there are fewer agreements: apparent agreements can also be illusory. ${ }^{1}$

What can we do about deep disagreements? Or, as Fogelin asks, "what rational procedures can be used for their resolution?" (Fogelin, 1985, 5). His answer is pessimistic: "The drift of this discussion leads to the answer: NONE" (ibid.). That does not mean that deep disagreements cannot be resolved but it does suggest that the resolution procedure may not be entirely rational. Fogelin quotes Wittgenstein's On Certainty: "I said I would 'combat' the other man-but wouldn't I give him reasons? Certainly; but how far do they go? At the end of reasons comes persuasion. (Think what happens when missionaries convert natives.)" (Wittgenstein, 1972, 9612). This is a somewhat sinister analogy for persuasion without reasons. Maybe a resolution could be found if one side succeeded in persuading the other, but such "persuasion" might be a higher price than we wish to pay. More recent authors have not all been so pessimistic. Scott Aikin has compiled this invaluable survey (Aikin, 2019, 421):

PESSIMISM: In deep disagreement, argument is impossible.

Non-engagement: In deep disagreements, one should not try to engage (Campolo, 2005, 2019).

\footnotetext{
${ }^{1}$ This echoes the "Abilene paradox" of deceptive agreement: in the eponymous example, a family of four talk themselves into a long, unpleasant drive in a Texas summer because each believes the others are in agreement that it is a good idea (Harvey, 1974).
} 
Polemical: In deep disagreements, one should use nonargumentative or alternative argumentative techniques (Kraus, 2012; Barris, 2015; Duran, 2016).

OPTIMISM: In deep disagreements, argument is possible and can be effective.

Prudential: One can discern deep disagreements only if one continues to argue; so one's defaults should be set on arguing (Adams, 2005).

Practical: Argument in deep disagreements prevents worse options (Lynch, 2010, 2012; Kappel, 2012; Jønch-Clausen and Kappel, 2015).

Arbitrational: Some deep disagreement cases can be resolved by an impartial third party (Memedi, 2007).

Supplemental: Argument in deep disagreement can produce or uncover shared reasons (Davson-Galle, 1992; Goodwin, 2005; Godden and Brenner, 2010).

Internal: Internal argument is still possible in deep disagreements (Finocchiaro, 2011; Zarefsky, 2012). ${ }^{2}$

Theoretical: Absolutely deep disagreements are impossible, since insofar as one can identify an other as one with whom one disagrees, one must see that other as one with whom one can argue (Feldman, 2005; Phillips, 2008; Siegel, 2014).

As we have seen, Fogelin is inclined to pessimism. I shall also pay most attention to the pessimistic response, although I note an ambiguity in what Aikin terms the polemical position: "alternative argumentative techniques" covers both alternatives to argumentation and alternative forms of argumentation.

\section{Prominence And Depth}

I shall suggest that some of the puzzles presented by deep disagreement can be at least clarified by a diversion into physical geography-specifically, the concept of "prominence", which Charley introduced in $\S 1 .{ }^{3}$ Here are two more technical (but equivalent) definitions of prominence:

(1) The minimum vertical distance one must descend from a point in order to reach a higher point.

(2) The difference between the elevation of a point, and the elevation of the lowest contour line that contains it and no higher point (Kirmse and de Ferranti, 2017, 788).

As we saw in $\S 1$, prominence explains why the world's second highest mountain is K2, not the South Peak of Everest, even though the latter is further above sea level than the former: lists of highest peaks have prominence thresholds. ${ }^{4}$ Prominence provides a measure of depth: how far down you have to climb before you can start climbing back up. Consider three peaks on an island, as in Fig. 1. The prominence of the highest peak is its height above sea level, since you would have to leave the island to find anything higher. The prominence of the second highest peak is its height above the highest col it shares with the highest peak and

\footnotetext{
${ }^{2}$ Finocchiaro defines an internal argument as one "in which one derives a conclusion not acceptable to an opponent from claims acceptable to him" (Finocchiaro, 2011, 32). In other words, it is Lockean ad hominem, or argument ex concessis, to which I will return in $\S 5$.

${ }^{3}$ The following account is based on that presented in (Aberdein, 2020).

${ }^{4}$ Traditionally, 100, 300, or $2000 \mathrm{ft}$ : worldwide more than seven million peaks meet the first threshold, over 250 times as many as meet the last (Kirmse and de Ferranti, 2017, 800).
} 
the prominence of the lowest peak is its height above the highest col it shares with the second highest peak. Hence the prominence of the lowest peak represents a lower bound on how far down individuals on the two lower peaks would need to climb in order to be on the same level. It is only a lower bound because the peaks may differ significantly in height. More generally, we might define the relative prominence of one peak with respect to some higher peak as its prominence ignoring all peaks of intermediate height. Thus, for any pair of peaks, the relative prominence of the lower peak is a lower bound on how far down individuals on each peak would need to climb to attain the same level.

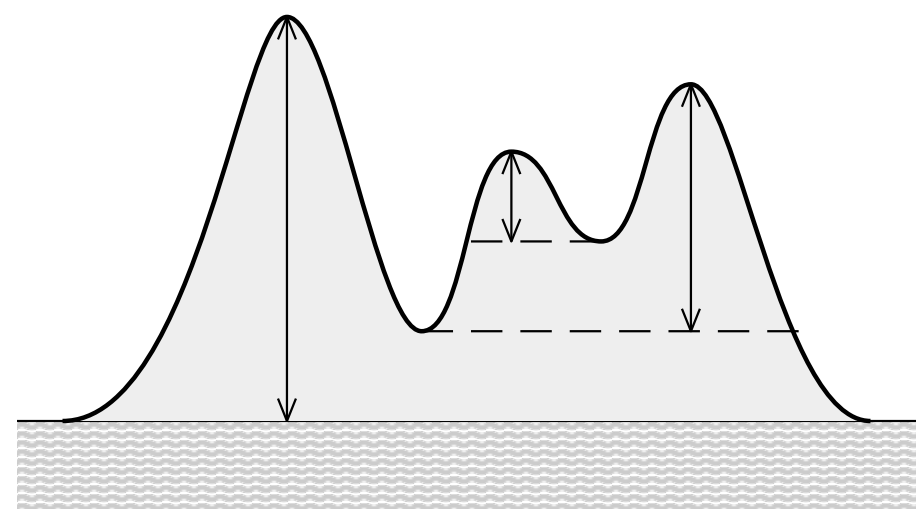

Figure 1. An island with three peaks: the vertical lines indicate the prominence of each peak; the horizontal lines the lowest contour line encircling it but no higher summit. (Adapted from https://en.wikipedia.org/wiki/Topographic_prominence.)

In order to draw an analogy with deep disagreement, we need an analogue for disagreement depth in terms of physical height. Some superficially plausible analogues for height may be ruled out. For example, it can't just be a measure of emotional intensity: as we have seen, deep disagreements are often heated, but not necessarily so. Nor can it be a measure on revision of belief sets: the proportion of each disputant's beliefs that would need to be suspended or revised in order for common ground to be reached. Although deeply disagreeing parties may disagree about many things, the scope of their disagreement need not be all that great. (Notoriously so, in some cases: the "narcissism of minor differences" (Freud, 1961, 68).) A more plausible candidate would be a measure on how deeply entrenched are the points of contention (or the principles upon which they depend) within each disputant's belief set (see Gärdenfors, 1988, 86 ff.). Only disagreements that reach the worldview of at least one of the disputants will count as deep. So, just as lists of peaks have prominence thresholds, we may now reserve "deep" for disagreements that exceed this threshold.

To summarize this topographic analogy, two disputants who at least suspend (dis)belief on the matters at issue for the duration of their argument are on shared level ground. Insofar as they sincerely disagree, either or both disputants stand on a summit from which they would need to climb down to reach level ground. For most disagreements, that is easy to do; but for deep disagreements, the descent will be an arduous endeavour, requiring substantial (and risky) restructuring of worldviews to accommodate revised epistemic principles. The contours of the terrain represent objective features of the disagreement. However, the disputants (or any other observer) may be mistaken as to where they stand: some 
cols are not as deep as they seem; others much deeper. Many disputants arrive at their summits by chance, others by choice. Notably, Mill's emotive arguers, whose disagreement "rests solely on feeling", purposefully avoid the level ground on which honest debate may take place by racing up (what they take to be) the highest available peak and refusing to descend.

\section{Arguing Virtuously or Viciously}

For the last decade or so, I have been one of several people making the case for a virtue theory of argumentation. Virtue theories and argumentation are as old as philosophy itself, perhaps older, but the explicit application of the former to the latter is a much more recent development. Most philosophical studies of argument emphasize technical aspects of argument success or failure, but they pay much less attention to the broader context of arguing, and generally ignore how the character of the people who take part in arguments bears on that success or failure. Virtue theories of argument seek to redress the balance, shifting the perspective away from arguments as products and onto arguers as people.

One way to explore the character of arguers is to look at their virtues and vices. Many instances of the traditional fallacies that logicians and argumentation theorists have been discussing since Aristotle can be analysed in terms of the vices of the arguer who employs them or the audience that falls for them (Aberdein, 2016). But arguers can exhibit other vices that lead arguments to malfunction in other ways. Some of these vices may correspond pretty closely to those familiar from ethical contexts: we may be cowardly in not defending a position we believe to be right, contemptuous of our opponent, or unfair in how we present an opposing position. Other vices may be unique to argumentation, such as unwillingness to revise our own position or unwillingness to engage in argument in the first place. A fuller inventory of the vices of argument promises to help explain how even the arguments that succeed by traditional lights can seem so unsatisfactory. Conversely, cultivation of the corresponding virtues of argument should improve the conduct and outcome of our arguments.

In virtue epistemology, a standard distinction is drawn between reliabilist (broadly externalist) and responsibilist (broadly internalist) conceptions of virtue (Axtell, 1997, 3). Heather Battaly helpfully reframes this as a distinction between virtues as requiring good ends and virtues as requiring good motives respectively (Battaly, 2015, 9). Of course, ideally, we would want virtuous activity both to be well-motivated and to bring about a good end. But we don't always get what we want: so Battaly argues that we should accept as virtues dispositions which only regularly meet one of these criteria. As an apposite example, consider the virtue of being willing to listen to others. An arguer might act in this way for ulterior motives, perhaps to receive a good grade in a speech class, or because their interlocutor told some good jokes. Nonetheless, their attentive listening might inadvertently lead them to contribute to a virtuous argument. Conversely, a wellmotivated arguer could be unselfishly willing to listen to others, but consistently unlucky in their choice of interlocutors, none of whom ever put forward an argument worth listening to, such that no good end ever came from the arguer's good motives. Obviously we hope to get both good ends and good motives, but we need to consider the cases where only one of these is to be had.

Daniel Cohen has been making the case for a virtue theory of argumentation as long as anyone. He proposes a set of negative exemplars: the deaf dogmatist, who won't listen to the arguments of others; the concessionaire, who loses arguments by being too ready to modify their own position, conceding things 
that weren't actually at issue; the eager believer, a forthright advocate for whatever position they heard last; the unassuring assurer, who seeks to reassure other parties who would not otherwise need reassurance-the "Not involved in human trafficking" T-shirt wearer of argumentation (Ginn, 2013); and the argument provocateur, who launches into arguments at the slightest opportunity, with or without regard to circumstances (Cohen, 2005, $61 \mathrm{ff}$.). Cohen characterizes some of these figures as tragic heroes rather than exemplars of vice: they are heroic, since there are important things they get right, but tragic, since their arguments seldom work out for the best. For example, the argument provocateur is at least willing to argue, even on sensitive matters where many others are unhelpfully reticent; the problem is that he is always willing to argue. What I will term Cohen's cardinal virtues of argument may be seen as means, each situated between a pair of negative exemplars that represent the corresponding vices of excess and deficiency. He distinguishes four such virtues: willingness to listen to others, willingness to modify your own position, willingness to question the obvious, and willingness to engage in serious argument. It is possible, but unnecessary for present purposes, to subdivide each of his cardinal virtues and their corresponding vices to include many other intellectual virtues and vices relevant to argumentation (for details, see Aberdein, 2016, 415 f.).

\section{Arrogance}

I now wish to turn to the vice of arrogance, that I will maintain is particularly relevant to a discussion of deep disagreement. Alessandra Tanesini draws a useful distinction "between haughtiness and arrogance. The first is manifested as disrespect toward other speakers; the second is an unwillingness to submit oneself to the norms governing ordinary conversation and rational debate" (Tanesini, 2016, 85). While these two attitudes are often found together, they are conceptually distinct, and it is arrogance that is the more revealing object of study. Tanesini proposes the following account of arrogance: "The speaker does not wish to imply that his mere saying so makes the content of the assertion true, but he is convinced that the mere fact that the assertion is his somehow secures its correctness" (Tanesini, 2016, 84). The idea is that the arrogant person treats his views as requiring a special sort of deference. There may be circumstances in which this makes sense-Tanesini suggests the umpire whose decisions are binding in a game (ibid.). Such an attitude is fine in that context, but few arguers are in that context. In general, anyone adopting this attitude will be disposed to insulate many (all?) of his beliefs from revision-a comprehensive failure of willingness to modify. Elsewhere Tanesini draws explicit implications for argumentation, or at least debate, from her account of intellectual arrogance (Tanesini, 2018, 222 ff.). The arrogant participant disregards the expected norms for the conduct of debate. Specifically, the arrogant arguer makes claims that lack the expected level of justification and ignores or dismisses calls to back up such claims; conversely an arrogant respondent may treat the arguer's claims as requiring an exceptional level of justification or dismiss them out of hand.

I wish to connect Tanesini's account of the arrogant arguer to two related approaches to arrogance. Firstly, Maura Priest has proposed an anti-asshole account of humility; she's defined humility as not being an asshole, which has an attractively blunt simplicity to it. She builds on Aaron James's definition: "a person counts as an asshole when, and only when, he systematically allows himself to enjoy special advantages in interpersonal relations out of an entrenched sense of entitlement that immunizes him against the complaints of other people" (James, 
2012, 4 f.). This has clear affinities with Tanesini's account of arrogance. Priest's intellectually humble person is thus someone who doesn't do that; someone who

- Respects the intellect of others as his own, and so rarely feels immune to their complaints and criticisms.

- Systematically declines intellectual advantages in interpersonal relations because he feels no sense of entitlement (Priest, 2017, 469).

She goes on to link arrogance to disregard for intellectual autonomy. This makes the arrogant person someone who cannot be trusted to use persuasion wisely: "Behaviors commonly associated with this disregard include deception and manipulation" (Priest, 2017, 474). Such actions undermine intellectual autonomy by manipulating persons into holding beliefs regardless of evidence or their own intellectual process.

Secondly, Nancy Potter, in defending a virtue account of trustworthiness, stresses the virtue of uptake:

To give uptake rightly, then, it is not enough simply to receive another's speech act with the conventional understanding. One must appreciate and respond to the spirit in which something is expressed, and one must take seriously what the speaker is trying to say and the speaker's reasons for saying it. One must have the appropriate emotional and intellectual responses, engaging one's whole heart. Furthermore, one must recognize the responsibility attending social and political privilege. Indeed, giving uptake properly is partly constitutive of the kind of person one is-it requires cultivation of a certain kind of character (Potter, 2002, 152).

Ultimately this idea is drawn from J. L. Austin, although it has mutated a fair bit en route (Austin, 1962, 116): unlike Austin, Potter characterizes uptake itself as a virtue. As such, uptake coincides closely with what Cohen and I call willingness to listen to others. It requires a suitable level of appreciative listening (cf. Rice, 2011). This seems like an antithesis of arrogance and, I suggest, the sort of virtue that is required in order to safely deploy tactics of persuasion that may resolve deep disagreements.

How does all this connect to deep disagreement? Firstly, any disagreement with an arrogant individual is more than likely to feel like deep disagreement, even in cases where there is an easily accessible resolution. The phenomenology of disagreeing with an arrogant person and of being in deep disagreement may be similarly frustrating, even though their ultimate cause is quite different. The origin of the arrogant arguer's unwillingness to back down and indifference to the assertions of others lies in his character, not in the subject matter of the dispute. Chris Campolo has expressed the worry that attempting to reason one's way out of a deep disagreement may do more harm than good (Campolo, 2019, 721). It can give rise to a misleading sense of common ground. In terms of my topographical analogy, such disagreements are concealed crevasses: the disputants believe that they are addressing their differences when they are really ignoring them. Any apparent resolution that may follow is likely to give way unexpectedly. Disagreements with arrogant arguers can present a converse problem: what may initially present as depth may be no more than intransigence. In topographical terms, this may be thought of as an invisible bridge: despite outward appearances, there is a safe path to common ground (even if some parties will be strongly resistant to using it). 
Secondly, but perhaps more seriously, the arrogant individual is a risk factor for some of the most promising strategies for resolution of deep disagreements. Specifically, it is precisely the behaviour of the arrogant arguer that gives rise to Wittgenstein's worries about the missionaries and the natives. Strategies that might find some way forward out of deep disagreement will, at the very least, go up to the edge of what counts as rational argument. Such strategies require particular care and attention. They are analogous to operating dangerous equipment with all the safety protocols turned off: the operator needs to be constantly vigilant about the associated risks. The arrogant person is entirely indifferent to those risks, at least so far as they impact others. Hence he will be the sort of person who gives persuasion a bad name, because, in so far as he has these techniques at his disposal, he will use them to twist others to his view. Conversely, the operation of the same techniques in conjunction with virtues that mitigate against these risks, such as willingness to listen to others, potentially represents a moral and practical way forward from deep disagreement.

As an example of a risky persuasion strategy consider "moral reframing". Recent social psychological research finds that "moral messages framed in a manner consistent with the moral values of those already supporting the political stance were less persuasive than moral arguments reframed to appeal to the values of the intended audience-those who typically oppose the political position that the messenger is arguing in favor of" (Feinberg and Willer, 2015, 1676). The empirical research suggests that if you present an argument from your own moral frame of reference then people who don't share that frame of reference may be unpersuaded, whereas if you reframe it in terms of your interlocutor's frame of reference then there is a greater chance of success. Of course, the empirical research is only concerned with determining if moral reframing is a successful technique, not whether it is a virtuous technique. One concern about moral reframing is that it is ad hominem, albeit in the least malign sense: Lockean ad hominem, or arguing from the concessions of the other party; "internal argument" as it was termed in §2. Even so, as Gary Jason observes of such arguments, "If I try to convince you of $C$ by citing P where you believe P, but I don't, I am being illogical. I am persuading you, not by sound argument, but by what I believe to be unsound argument" (Jason, 1984, 185). I would not be arguing unsoundly if, instead of arguing for $C$ on the basis of $\mathrm{P}$, I were to argue for "If $\mathrm{P}$ then $\mathrm{C}$ ", which I believe to be true, and leave you to infer $C$ from your (mistaken, by my lights) belief that P. Nonetheless, I would still be reconciling myself to your coming to believe $C$ on the basis of what I take to be an unsound argument. This may seem a somewhat recondite concern, but if you judge your opponents' values to be intrinsically reprehensible, then employing them in argument, however hypothetically, would be inconsistent with your own values. For example, Sherman Clark considers a critic of a new subway line, whose own opposition is grounded in economic arguments, but who is tempted to persuade others with "a subtle appeal to race-based fear-perhaps by hinting at or subtly evoking visions of 'thugs' from the other side of town having easier access to good neighborhoods" (Clark, 2011, 852). As Clark observes "you might also quite sensibly realize that by making that sort of argument, even and perhaps especially if you did so indirectly and subtly, you would not just be appealing to but also helping to construct and reinforce fear and prejudice" (ibid.). So that sort of moral reframing would be not only vicious, but a cause of vice in others. Nonetheless, Clark is not denouncing moral reframing; on the contrary, he elsewhere states that "if we hope to be persuasive, we have no choice but to navigate the worldviews of those we hope to persuade", but he also proposes that if we "truly engage with those we hope to reach, we might 
find that many people would respond as well or better to nobler appeals" (Clark, 2003, 73 f.). Used judiciously, moral reframing has the potential to be a constructive strategy for dealing with deep disagreement. But its associated risks show the importance of close attention to argumentative virtues in its deployment.

\section{Conclusion}

The dialogue in $\S 1$ may end in more than one way. Alice and Bob could continue to sketch out competing worldviews without getting any closer together: a classic deep disagreement. Alternatively, it might become clear that one of them is refusing to back down from arrogance, not epistemic principle. In that case, the disagreement need not be deep, although it may prove just as hard to resolve. Or, in either of these cases, Alice or Bob may succeed in persuading the other. Such persuasion may involve techniques that go beyond argumentation, at least as narrowly defined. If either of them succumbs to arrogance, such persuasion may be no more than browbeating. Winning the argument on these terms provides no reason to think the winner is in the right epistemically (and good reason to think they're in the wrong ethically). But, if such persuasion is conducted with humility, and the other attendant virtues of argument, it may lead the other party to a sincere shift of worldview. That may not count for much if all that's at stake is the identity of the world's second highest mountain, but on more worldly matters it can be of paramount importance.

\section{REFERENCES}

Aberdein, Andrew. 2016. The vices of argument. Topoi 35(2): 413-422.

Aberdein, Andrew. 2020. Courageous arguments and deep disagreements. Topoi Forthcoming.

Adams, David M. 2005. Knowing when disagreements are deep. Informal Logic 25(1): 65-77.

Aikin, Scott F. 2019. Deep disagreement, the dark enlightenment, and the rhetoric of the red pill. Journal of Applied Philosophy 36(3): 420-435.

Austin, John Langshaw. 1962. How To Do Things With Words. Oxford: Oxford University Press.

Axtell, Guy. 1997. Recent work in virtue epistemology. American Philosophical Quarterly 34(1): 1-27.

Barris, Jeremy. 2015. Metaphysics, deep pluralism, and paradoxes of informal logic. International Journal of Philosophical Studies 23(1): 59-84.

Battaly, Heather. 2015. A pluralist theory of virtue. In Current Controversies in Virtue Theory, ed. Mark Alfano, 7-22. London: Routledge.

Campolo, Chris. 2005. Treacherous ascents: On seeking common ground for conflict resolution. Informal Logic 25(1): 37-50.

Campolo, Chris. 2019. On staying in character: Virtue and the possibility of deep disagreement. Topoi 38(4): 719-723.

Clark, Sherman J. 2003. The character of persuasion. Ave Maria Law Review 1(1): 61-79.

Clark, Sherman J. 2011. What we make matter. Michigan Law Review 109(6): 849862.

Cohen, Daniel H. 2005. Arguments that backfire. In The Uses of Argument, eds. David Hitchcock and Daniel Farr, 58-65. Hamilton, ON: OSSA.

Davson-Galle, Peter. 1992. Arguing, arguments, and deep disagreements. Informal Logic 14(2-3): 147-156. 
Duran, Claudio. 2016. Levels of depth in deep disagreement. In Argumentation, Objectivity and Bias: Proceedings of the 11th International Conference of the Ontario Society for the Study of Argumentation (OSSA), May 18-21, 2016, eds. Patrick Bondy and Laura Benacquista. Windsor, ON: OSSA.

Feinberg, Matthew and Robb Willer. 2015. From gulf to bridge: When do moral arguments facilitate political influence? Personality and Social Psychology Bulletin 41(12): 1665-1681.

Feldman, Richard. 2005. Deep disagreement, rational resolutions, and critical thinking. Informal Logic 25(1): 13-23.

Finocchiaro, Maurice A. 2011. Deep disagreements: A meta-argumentation approach. In Argumentation: Cognition \& Community. Proceedings of the gth International Conference of the Ontario Society for the Study of Argumentation (OSSA), May 18-21, 2011, ed. Frank Zenker. Windsor, ON: OSSA.

Fogelin, Robert J. 1985. The logic of deep disagreements. Informal Logic 7(1): 1-8. Freud, Sigmund. 1961. Civilization and its Discontents. New York, NY: W. W. Norton. Translated by James Strachey.

Gärdenfors, Peter. 1988. Knowledge in Flux: Modeling the Dynamics of Epistemic States. Cambridge, MA: The MIT Press.

Ginn, Mike (@shutupmikeginn). 2013. My "Not involved in human trafficking" T-shirt has people asking a lot of questions already answered by my shirt. URL https://twitter.com/shutupmikeginn/status/403359911481839617. November 20 2013, 10:11 p.m. Tweet.

Godden, David and William H. Brenner. 2010. Wittgenstein and the logic of deep disagreement. Cogency 2(2): 41-80.

Goodwin, Jean. 2005. Designing premises. In Argumentation in Practice, eds. Frans H. van Eemeren and Peter Houtlosser, 99-114. Amsterdam: John Benjamins Publishing.

Hannon, Michael. 2019. Are political disagreements real disagreements? Quillette Online at https://quillette.com/2019/08/20/ are-political-disagreements-real-disagreements/.

Hannon, Michael. 2020. Political disagreement or partisan badmouthing? The role of expressive discourse in politics. In Routledge Handbook of Political Epistemology, eds. Michael Hannon and Jeroen de Ridder. London: Routledge. Forthcoming.

Harvey, Jerry B. 1974. The Abilene paradox: The management of agreement. Organizational Dynamics 3(1): 63-80.

James, Aaron. 2012. Assholes: A Theory. New York, NY: Doubleday.

Jason, Gary James. 1984. Is there a case for ad hominem arguments? Australasian Journal of Philosophy 62(2): 182-185.

Jønch-Clausen, Karin and Klemens Kappel. 2015. Social epistemic liberalism and the problem of deep epistemic disagreements. Ethical Theory and Moral Practice 18: $371-384$.

Kappel, Klemens. 2012. The problem of deep disagreement. Discipline Filosofiche 22(2): 7-25.

Kirmse, Andrew and Jonathan de Ferranti. 2017. Calculating the prominence and isolation of every mountain in the world. Progress in Physical Geography 41(6): 788-802.

Kraus, Manfred. 2012. Cultural diversity, cognitive breaks, and deep disagreement: Polemic argument. In Topical Themes in Argumentation Theory, eds. Frans H. van Eemeren and Bart Garssen, 91-107. Dordrecht: Springer.

Lynch, Michael P. 2010. Epistemic circularity and epistemic incommensurability. In Social Epistemology, eds. A. Haddock, A. Millar, and D. Pritchard, 262-277. 
Oxford: Oxford University Press.

Lynch, Michael P. 2012. In Praise of Reason: Why Rationality Matters for Democracy. Cambridge, MA: MIT Press.

Memedi, Vesel. 2007. Resolving deep disagreement. In Dissensus and the Search for Common Ground, ed. Hans V. Hansen. Windsor, ON: OSSA.

Mill, John Stuart. 1977 [1869]. The subjection of women. In Collected Works of John Stuart Mill, ed. J. M. Robson, vol. 21, 259-340. Toronto: University of Toronto Press.

Phillips, Dana. 2008. Investigating the shared background required for argument: A critique of Fogelin's thesis on deep disagreement. Informal Logic 28(2): 86101.

Potter, Nancy Nyquist. 2002. How Can I Be Trusted? A Virtue Theory of Trustworthiness. Lanham, MD: Rowman \& Littlefield.

Priest, Maura. 2017. Intellectual humility: An interpersonal theory. Ergo 4(16): $463-480$.

Rice, Suzanne. 2011. Toward an Aristotelian conception of good listening. Educational Theory 61(2): 141-153.

Schaffner, Brian F and Samantha Luks. 2018. Misinformation or expressive responding? What an inauguration crowd can tell us about the source of political misinformation in surveys. Public Opinion Quarterly 82(1): 135-147.

Siegel, Harvey. 2014. Argumentation and the epistemology of disagreement. In Virtues of Argumentation: Proceedings of the 1oth International Conference of the Ontario Society for the Study of Argumentation (OSSA), May 22-25, 2013, eds. Dima Mohammed and Marcin Lewiński. Windsor, ON: OSSA.

Tanesini, Alessandra. 2016. "Calm down, dear": Intellectual arrogance, silencing and ignorance. Proceedings of the Aristotelian Society Supp. Vol. 90: 71-92.

Tanesini, Alessandra. 2018. Arrogance, anger and debate. Symposion 5(2): 213227.

Wittgenstein, Ludwig. 1972. On Certainty. New York, NY: Harper \& Row.

Zarefsky, David. 2012. The appeal for transcendence: A possible response to cases of deep disagreement. In Topical Themes in Argumentation Theory, eds. Frans H. van Eemeren and Bart Garssen, 77-89. Dordrecht: Springer. 